\title{
NeuroImage
}

\section{Dissociating neural correlates for nouns and verbs}

\author{
Kevin A. Shapiro, ${ }^{\mathrm{a}, 1}$ Felix M. Mottaghy, ${ }^{\mathrm{b}, 1}$ Niels O. Schiller, ${ }^{\mathrm{c}, \mathrm{d}}$ Thorsten D. Poeppel, ${ }^{\mathrm{b}}$ \\ Michael O. Flüß, ${ }^{b}$ H.-W. Müller, ${ }^{\text {b Alfonso Caramazza, }{ }^{a} * \text { and Bernd J. Krause }}{ }^{b}$ \\ ${ }^{a}$ Department of Psychology, Harvard University, William James Hall 930, 33 Kirkland Street, Cambridge, MA 02138, USA \\ ${ }^{\mathrm{b}}$ Department of Nuclear Medicine (KME), Heinrich Heine University and Research Center Jülich, D-52426 Jülich, Germany \\ ${ }^{\mathrm{c}}$ Department of Psychology, University of Maastricht, NL-6200 MD Maastricht, Netherlands \\ ${ }^{\mathrm{d}}$ Max Planck Institute for Psycholinguistics, NL-6500 AH Nijmegen, Netherlands
}

Received 21 April 2004; revised 12 October 2004; accepted 18 October 2004

Available online 28 December 2004

\begin{abstract}
Dissociations in the ability to produce words of different grammatical categories are well established in neuropsychology but have not been corroborated fully with evidence from brain imaging. Here we report on a PET study designed to reveal the anatomical correlates of grammatical processes involving nouns and verbs. German-speaking subjects were asked to produce either plural and singular nouns, or first-person plural and singular verbs. Verbs, relative to nouns, activated a left frontal cortical network, while the opposite contrast (nouns-verbs) showed greater activation in temporal regions bilaterally. Similar patterns emerged when subjects performed the task with pseudowords used as nouns or as verbs. These results converge with findings from lesion studies and suggest that grammatical category is an important dimension of organization for knowledge of language in the brain.
\end{abstract}

(C) 2004 Elsevier Inc. All rights reserved.

Keywords: Noun; Verb; Neural correlates

\section{Introduction}

Numerous neuropsychological case reports have shown that language processing following brain damage occasionally breaks down along lines of grammatical category. Some aphasic patients (most often those with damage affecting the left frontal cortex) have more difficulty producing and comprehending verbs than nouns, while others (typically with left temporal and parietal lesions) show the reverse dissociation (Caramazza and Hillis, 1991; Damasio and Tranel, 1993; Daniele et al., 1994; Goodglass et al., 1966; Luria and Tsvetkova, 1967; Miceli et al., 1984).

\footnotetext{
* Corresponding author. Fax: +1 6174966262.

E-mail address: caram@wjh.harvard.edu (A. Caramazza).

${ }^{1}$ These authors contributed equally to the study.

Available online on ScienceDirect (www.sciencedirect.com).
}

Although there are important exceptions to this lesion-deficit pattern, the very existence of a double dissociation between nouns and verbs in aphasia provides good evidence that distinct brain mechanisms are involved in producing words of each category.

The nature of this distinction, however, is not well understood. Some researchers have suggested that noun-verb dissociations reflect salient differences in the neural representation of objects and actions (Damasio and Tranel, 1993; McCarthy and Warrington, 1985; Pulvermuller, 1999). In other words, they propose that the brain distinguishes between nouns and verbs on the basis of semantics (meaning), not of grammatical category as such. Others hold that the brain also represents information about a word's syntactic function, and that this information is susceptible to selective impairment (Caramazza and Hillis, 1991; Miceli et al., 1984; Shapiro et al., 2000). It therefore remains unclear whether brain regions damaged in patients with noun and verb deficits subserve knowledge about word meaning, grammatical function, or both.

Attempts to shed light on these issues with studies of neurologically intact subjects have so far yielded mixed results. Electrophysiological evidence suggests that different neural populations are active in noun and verb processing (Koenig and Lehmann, 1996), even when factors correlated with meaning are controlled (Kellenbach et al., 2002). Along similar lines, a recent study with transcranial magnetic stimulation (TMS) showed that suppression of the left prefrontal cortex disrupted verb production but not noun production (Shapiro et al., 2001). The same pattern held for pseudowords used as nouns and verbs, suggesting that this dissociation was driven by grammatical aspects of word production and not by processes related to the retrieval of stored meanings for action and object words.

A few neuroimaging studies have reported cortical differences in processing words that refer to actions and objects (Grossman et al., 2002; Kable et al., 2002; Tranel et al., 1997) (although some have not; cf. Warburton et al., 1996). However, in studies where some attempt has been made to disentangle effects of semantic factors like concreteness from effects of grammatical category as 
Table 1

Areas in which greater activation was observed for morphological processing (of nouns, verbs, and pseudowords) than for a reference task in which pseudowords were produced without morphological change ${ }^{a}$

\begin{tabular}{|c|c|c|c|c|c|c|}
\hline \multirow[t]{2}{*}{ Anatomical region } & \multicolumn{3}{|c|}{ Talairach coordinates } & \multirow[t]{2}{*}{$k$} & \multicolumn{2}{|l|}{ SVC } \\
\hline & $x$ & $y$ & $z$ & & $T$ & $P$ \\
\hline $\begin{array}{l}\text { Left inferior frontal } \\
\text { gyrus/middle frontal } \\
\text { gyrus }\end{array}$ & -59 & 9 & 29 & 98 & 3.81 & 0.007 \\
\hline $\begin{array}{l}\text { Medial frontal gyrus/ } \\
\text { anterior cingulate } \\
\text { cortex }\end{array}$ & 0 & 2 & 48 & 61 & 3.42 & 0.013 \\
\hline Left precentral gyrus & -36 & -21 & 49 & 28 & 3.16 & 0.023 \\
\hline Right cerebellum & 12 & -67 & -24 & 30 & 3.20 & 0.023 \\
\hline
\end{tabular}

${ }^{\text {a For all tables: } x, y \text {, and } z \text { are the Talairach coordinates of the center of }}$ gravity of the reported cluster; $k=$ cluster size; $T=$ significance level of the reported cluster $(d f=43) ; \mathrm{SVC}=$ small volume correction; $P=P$ value of the SVC.

such (Perani et al., 1999; Tyler et al., 2001), spatially distinct patterns of activation for nouns and verbs have not been found.

One reason for this puzzling negative finding might be that the tasks used in neuroimaging studies to date have engaged processing mechanisms that do not distinguish between nouns and verbs. Language relies on a distributed cortical network, with different functional and anatomical components involved in processing information about word meaning, sound structure, and syntactic properties. Not all of these components need to be sensitive to the grammatical category of a word being produced, and it is possible that tasks like lexical decision (Perani et al., 1999; Tyler et al., 2001) and semantic categorization (Tyler et al., 2001), even in carefully designed studies, are not appropriate to reveal categorical differences between nouns and verbs. None of these

Table 2

Areas with greater activation during production of either nouns or verbs ${ }^{\mathrm{a}}$

\begin{tabular}{|c|c|c|c|c|c|c|}
\hline \multirow[t]{2}{*}{ Anatomical region } & \multicolumn{3}{|c|}{ Talairach coordinates } & \multirow[t]{2}{*}{$k$} & \multicolumn{2}{|l|}{ SVC } \\
\hline & $x$ & $y$ & $z$ & & $T$ & $P$ \\
\hline \multicolumn{7}{|l|}{ Verbs $>$ nouns } \\
\hline $\begin{array}{l}\text { Left superior } \\
\text { temporal gyrus }\end{array}$ & -32 & 14 & -28 & 111 & 3.40 & 0.024 \\
\hline $\begin{array}{l}\text { Left inferior } \\
\text { frontal gyrus }\end{array}$ & -24 & 23 & -5 & 27 & 2.71 & 0.043 \\
\hline $\begin{array}{l}\text { Left superior } \\
\text { frontal gyrus }\end{array}$ & -16 & 48 & 20 & 263 & 3.31 & 0.050 \\
\hline Right cerebellum & 16 & -83 & -29 & 73 & 2.99 & 0.042 \\
\hline Left insula & -40 & -34 & 20 & 64 & 2.88 & 0.067 \\
\hline \multicolumn{7}{|l|}{ Nouns $>$ verbs } \\
\hline $\begin{array}{l}\text { Right superior } \\
\text { temporal gyrus }\end{array}$ & 63 & -4 & $\mathbf{0}$ & 136 & 3.53 & 0.018 \\
\hline Right insula & 36 & 16 & 7 & 24 & 2.93 & 0.019 \\
\hline $\begin{array}{l}\text { Right superior } \\
\text { temporal gyrus }\end{array}$ & 67 & -27 & 12 & 24 & 2.84 & 0.025 \\
\hline Left fusiform gyrus & -28 & -36 & -15 & 124 & 3.19 & 0.045 \\
\hline Left thalamus & -16 & -11 & 12 & 20 & 2.83 & 0.024 \\
\hline Right cerebellum & 24 & -59 & -17 & 61 & 3.40 & 0.012 \\
\hline Right postcentral gyrus & 48 & -18 & 27 & 24 & 2.37 & 0.072 \\
\hline Left lingual gyrus & -8 & -89 & -2 & 26 & 2.27 & 0.091 \\
\hline
\end{tabular}

${ }^{a}$ Activations that survive an SVC are in bold.
Table 3

Areas with greater activation during production of either pseudoverbs or pseudonouns

\begin{tabular}{|c|c|c|c|c|c|c|}
\hline \multirow[t]{2}{*}{ Anatomical region } & \multicolumn{3}{|c|}{ Talairach coordinates } & \multirow[t]{2}{*}{$k$} & \multicolumn{2}{|l|}{ SVC } \\
\hline & $x$ & $y$ & $z$ & & $T$ & $P$ \\
\hline \multicolumn{7}{|c|}{ Pseudoverbs $>$ pseudonouns } \\
\hline $\begin{array}{l}\text { Left superior } \\
\text { frontal gyrus }\end{array}$ & -28 & 44 & 27 & 132 & 3.10 & 0.050 \\
\hline $\begin{array}{l}\text { Right middle } \\
\text { temporal gyrus }\end{array}$ & 40 & 2 & -37 & 29 & 2.65 & 0.044 \\
\hline Left cerebellum & -44 & -64 & -27 & 68 & 2.98 & 0.044 \\
\hline $\begin{array}{l}\text { Right middle } \\
\text { temporal gyrus }\end{array}$ & 51 & -35 & -2 & 27 & 2.60 & 0.054 \\
\hline Left insula & -36 & 8 & 11 & 21 & 2.35 & 0.075 \\
\hline Left fusiform gyrus & -28 & -40 & -22 & 200 & 3.10 & 0.095 \\
\hline \multicolumn{7}{|c|}{ Pseudonouns > pseudoverbs } \\
\hline $\begin{array}{l}\text { Left inferior } \\
\text { frontal gyrus }\end{array}$ & -59 & 13 & 21 & 20 & 2.90 & 0.021 \\
\hline $\begin{array}{l}\text { Right superior } \\
\text { temporal gyrus }\end{array}$ & 63 & -8 & 4 & 436 & 4.20 & 0.008 \\
\hline Left insula & -44 & -19 & 1 & 51 & 2.84 & 0.049 \\
\hline Left cerebellum & -16 & -63 & -24 & 27 & 2.93 & 0.023 \\
\hline $\begin{array}{l}\text { Right middle } \\
\text { temporal gyrus }\end{array}$ & 59 & -28 & -15 & 26 & 2.29 & 0.100 \\
\hline Left precentral gyrus & -28 & -25 & 49 & 48 & 2.35 & 0.154 \\
\hline Left postcentral gyrus & -8 & -36 & 57 & 34 & 2.13 & 0.184 \\
\hline
\end{tabular}

previous studies employed tasks that specifically tapped subjects' grammatical knowledge about words.

We therefore chose to investigate, using PET, the neural correlates of noun and verb processing in normal subjects. We employed a task that involves simple grammatical operations: namely, producing singular and plural forms of nouns and firstperson singular and plural forms of verbs. Subjects were presented with the written form of a word [e.g., FAHNE (flag); KAUFE (I buy)], followed by a symbolic cue indicating the form of the word to be produced. They then produced the word aloud with the appropriate morphological inflection ["fahnen" (flags); "kaufen" (we buy)]. It has been shown that similar tasks are sensitive to grammatical category-specific disruptions caused by TMS (Shapiro et al., 2001) or focal brain lesions (Shapiro et al., 2000).

Table 4a

Areas with greater activation during production of verbs and pseudoverbs than of nouns and pseudonouns

\begin{tabular}{|c|c|c|c|c|c|c|}
\hline \multirow[t]{2}{*}{ Anatomical region } & \multicolumn{3}{|c|}{$\underline{\text { Talairach coordinates }}$} & \multirow[t]{2}{*}{$k$} & \multicolumn{2}{|l|}{$\underline{\mathrm{SVC}}$} \\
\hline & $x$ & $y$ & $z$ & & $T$ & $P$ \\
\hline \multicolumn{7}{|c|}{$($ Verbs + pseudoverbs $)>$ (nouns + pseudonouns $)$} \\
\hline $\begin{array}{l}\text { Left superior } \\
\text { frontal gyrus }\end{array}$ & -20 & 48 & 27 & 323 & 3.84 & 0.017 \\
\hline $\begin{array}{l}\text { Left superior } \\
\text { temporal gyrus }\end{array}$ & -36 & 7 & -24 & 38 & 2.85 & 0.043 \\
\hline Left cerebellum & -51 & -64 & -34 & 35 & 2.97 & 0.027 \\
\hline Right cerebellum & 44 & -64 & -30 & 52 & 2.96 & 0.036 \\
\hline Left thalamus & -28 & -31 & 9 & 28 & 2.74 & 0.045 \\
\hline $\begin{array}{l}\text { Left superior } \\
\text { temporal gyrus }\end{array}$ & -44 & -49 & 25 & 54 & 2.72 & 0.069 \\
\hline Left cerebellum & -28 & -44 & -31 & 20 & 2.21 & 0.090 \\
\hline Right cerebellum & 16 & -79 & -20 & 31 & 2.11 & 0.172 \\
\hline
\end{tabular}


Table $4 b$

Areas with greater activation during production of nouns and pseudonouns than of verbs and pseudoverbs

\begin{tabular}{|c|c|c|c|c|c|c|}
\hline \multirow[t]{2}{*}{ Anatomical region } & \multicolumn{3}{|c|}{ Talairach coordinates } & \multirow[t]{2}{*}{$k$} & \multicolumn{2}{|l|}{ SVC } \\
\hline & $x$ & $y$ & $z$ & & $T$ & $P$ \\
\hline \multicolumn{7}{|c|}{ (Nouns + pseudonouns $)>($ verbs + pseudoverbs $)$} \\
\hline $\begin{array}{l}\text { Right superior } \\
\text { temporal gyrus }\end{array}$ & 63 & -8 & 0 & 408 & 5.25 & 0.00 \\
\hline $\begin{array}{l}\text { Left fusiform } \\
\text { gyrus }\end{array}$ & -28 & -36 & -12 & 49 & 3.42 & 0.01 \\
\hline $\begin{array}{l}\text { Left precentral } \\
\text { gyrus }\end{array}$ & -28 & -21 & 53 & 26 & 2.76 & 0.0 \\
\hline Left cerebellum & -16 & -63 & -20 & 40 & 2.94 & 0.029 \\
\hline $\begin{array}{l}\text { Left precentral } \\
\text { gyrus }\end{array}$ & -12 & -31 & 72 & 25 & 2.55 & 0.060 \\
\hline $\begin{array}{l}\text { Left medial } \\
\text { frontal gyrus }\end{array}$ & -4 & 30 & -15 & 29 & 2.43 & 0.08 \\
\hline Left insula & -44 & -16 & 1 & 159 & 3.01 & 0.08 \\
\hline
\end{tabular}

Subjects also performed the task with pseudowords (e.g., BRAHLE) used as nouns and verbs. Since pseudowords have no semantic content, activation differences that emerge in processing these items as nouns or verbs must reflect the recruitment of neural mechanisms selective for each grammatical category.

\section{Materials and methods}

\section{Subjects}

Twelve subjects (6 male and 6 female) participated in the experiment. All were healthy, right-handed native speakers of German with no history of neurological or psychiatric disorders. Written informed consent was obtained according to protocols approved by the Ethics Commission of Heinrich Heine University (Düsseldorf, Germany) and the Committee on the Use of Human Subjects in Research at Harvard University (Cambridge, USA). The study was also approved by German legal authorities.

\section{Experimental design}

The set of real words used in the experiment consisted of 20 unambiguous nouns and 20 unambiguous verbs, all two syllables in length and matched across category for surface frequency, number of letters, and number of phonological segments. All of the nouns had feminine gender, with singular forms ending in /e/ and plural forms ending in /en/. Though nouns of this type are sometimes considered formally irregular, experimental evidence suggests that both neurologically intact and aphasic speakers treat them as regular (Penke and Krause, 2002). The verbs were all morphologically regular. A set of 40 phonologically licit pseudowords was matched to these words in letter and phoneme length.

After subjects were placed on the bed of the scanner, several training trials were conducted to get them acquainted with the task. The room was dimly lit. The task was presented at the center of a monitor placed at eye level $1 \mathrm{~m}$ in front of the subjects, using the Nijmegen Experimental Set-Up (NESU) developed at the Max Planck Institute for Psycholinguistics. Items were presented in black 36 point Arial font against a white background. Accuracy of task performance was recorded.

The task began with a fixation cross at the center of the screen. In each trial, the subject viewed a written stimulus word (either a noun or a verb), which appeared in the position of the fixation point for $250 \mathrm{~ms}$, followed for another $250 \mathrm{~ms}$ by a symbolic cue indicating the morphological form in which the word was to be produced aloud-singular $(*)$ or plural $(* * *)$ for nouns, firstperson singular $(*)$ or plural $(* * *)$ for verbs. Note that this operation is phonologically equivalent for nouns and verbs: singular forms always end in /e/, and plural forms always end in /en/. When pseudowords were used, subjects were instructed as to whether the stimuli should be regarded as (feminine) nouns or verbs; otherwise, the task was identical with real words and pseudowords. For each subject, half (20) of the 40 pseudoword stimuli were used in the noun condition (i.e., subjects were instructed to produce them as nouns); the other half were used in the verb condition. The assignment of a given pseudoword stimulus to either the noun or the verb condition was varied for each participant. Across subjects, therefore, the pseudonoun and pseudoverb conditions were equivalent in orthographic complexity and all other relevant dimensions.

The intertrial interval was $3 \mathrm{~s}$. The task began $15 \mathrm{~s}$ before intravenous administration of the tracer to ensure the achievement of a behavioral "steady state" at the time of the tracer's arrival into the brain (approximately 11-18 s after the iv administration).

The experiment was divided into six blocks, with 40 trials in each block. Subjects performed the task described above with nouns (N), verbs $(\mathrm{V})$, pseudonouns $(\mathrm{PN})$, and pseudoverbs (PV) in separate blocks. In the fifth block, subjects were presented with pseudowords followed by congruent cues and were instructed to read the

Table 5

Summary of significant cortical activations across all comparisons; $P$ values are given for small volume corrections $(\mathrm{BA}=\mathrm{Brodmann}$ areas corresponding to centers of gravity of the reported activations)

\begin{tabular}{lllcc}
\hline Cortical region & BA & V & PV & V PV \\
\hline Left superior frontal gyrus & 9 & 0.050 & 0.050 & 0.017 \\
Left inferior frontal gyrus & $45 / 47$ & 0.043 & & 0.043 \\
Left superior temporal gyrus & 38 & & 0.044 & 0.021 \\
Right middle temporal gyrus & 38 & & 0.018 \\
Right superior temporal gyrus & $22 / 42$ & & 0.045 \\
Left fusiform gyrus & $20 / 37$ & & 0.019 \\
Right insula & 13 & & 0.00 \\
Left insula & 13 & & 0.049 \\
Right fusiform gyrus & 19 & & 0.022 \\
Left precentral gyrus & 4 & & 0.034 \\
\hline
\end{tabular}


pseudowords aloud without any morphological manipulation (B). In the sixth block, subjects passively viewed pseudowords followed by cues. This condition was not introduced into the analysis. The order of the blocks varied across subjects in a multiple Latin square fashion.

\section{Image acquisition}

Prior to inclusion into the PET study, 3-D MPRAGE highresolution MRI scans were obtained. All subjects had scans without any abnormalities. The MRI data sets were further employed in the normalization procedure during the processing of the data. During the PET study, six emission scans were acquired in each subject. The time between scans was 10 min to allow sufficient decay of radioactivity. A CTI/Siemens ECAT EXACT $\mathrm{HR}+$ PET scanner with 32 detector rings in 3-D mode was used. The axial field of view measures $15.5 \mathrm{~cm}$. The physical characteristics of this scanner have been described (Brix et al., 1997). One transmission scan was performed with 3 rotating ${ }^{68} \mathrm{Ga} /{ }^{68} \mathrm{Ge}$ line sources for measured attenuation correction. To improve image reconstruction quality, the transmission scans were aligned with the emission scans before attenuation correction was performed. On each of the six scans, an intravenous bolus of $555 \mathrm{MBq}{ }^{15} \mathrm{O}$-butanol (half-life $123 \mathrm{~s}$ ) was administered (Herzog et al., 1994). Dynamic emission data were acquired for $80 \mathrm{~s}$ with time frames of $20 \mathrm{~s}$ starting with the intracerebral arrival of the tracer using an absolute threshold above background count rate. For further data processing, the first two frames were summed into a single frame representing $40 \mathrm{~s}$. Data were reconstructed using filtered back projection. All reconstructions used the PROMIS algorithm (Kinahan and Rogers, 1989) with a radial Hann filter and an axial all pass filter with a cutoff frequency of 0.33 cycles/pixel each. All corrections were applied, including attenuation correction with measured transmission. A $128 \times 128$ matrix was chosen with 63 transverse slices covering a total of $15.5 \mathrm{~cm}$. The image resolution was $7 \mathrm{~mm}$ full-width half maximum (FWHM). The activity images were not further quantified and were regarded as estimates of $\mathrm{rCBF}$.

\section{Statistical analysis}

The preprocessed PET data were introduced into a spatial normalization $\left(4 \times 4 \times 4 \mathrm{~mm}^{3}\right.$ isotropic voxels; the parameters were

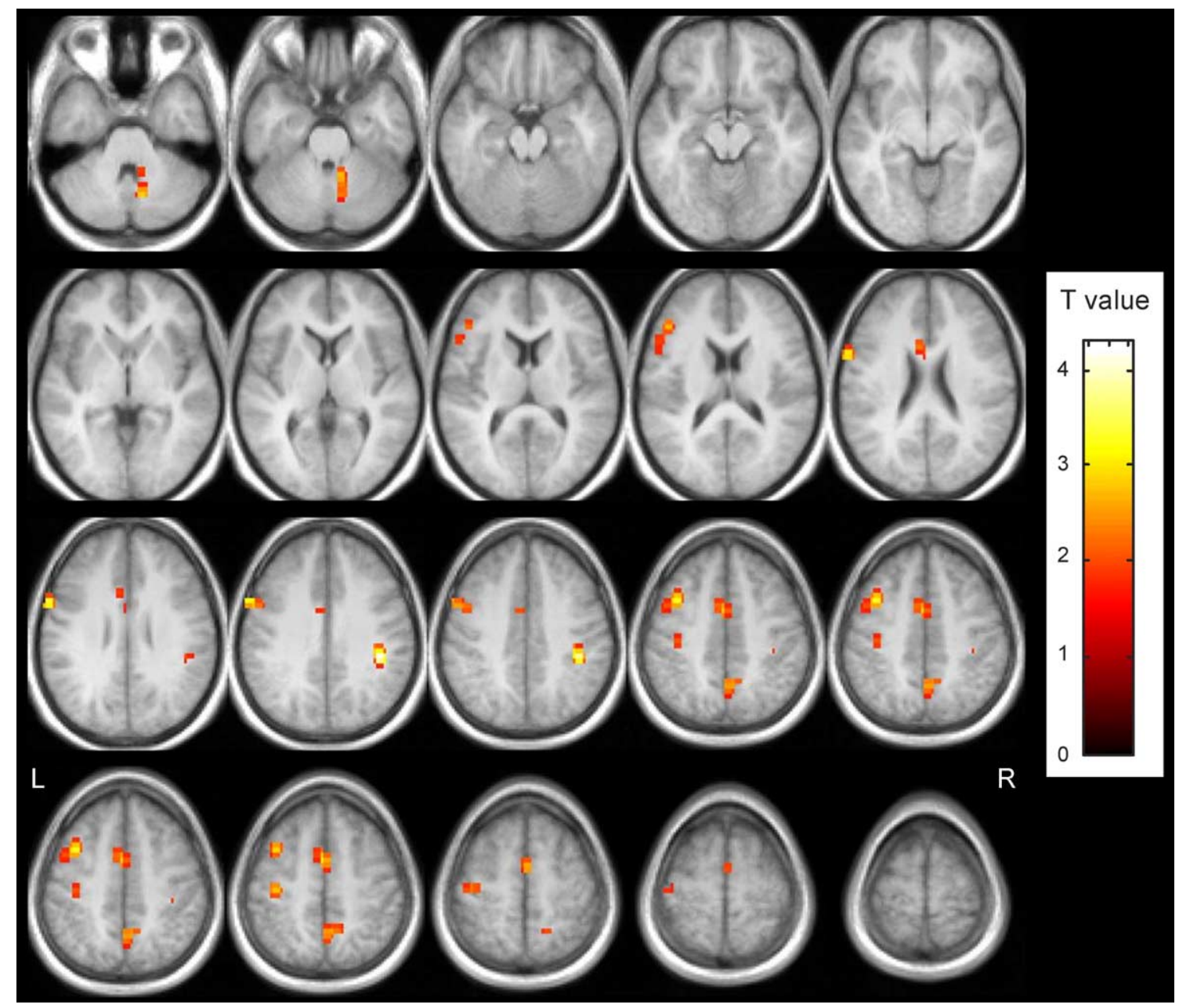

Fig. 1. Activation common to all grammatical processing conditions (noun [N], verb [V], pseudonoun [PN], and pseudoverb [PV]) compared to a reference condition in which subjects produced pseudowords without morphological change, superimposed on the mean anatomical image of all 12 subjects $(P<$ $0.01 ; k=20$ ). 
determined from the individual MRI) and smoothing (FWHM = $15 \mathrm{~mm}$ ) procedure using SPM99 (The Wellcome Department of Cognitive Neurology, London, UK). The 3-D template (MNI) used in SPM99 has slightly different dimensions in comparison to the Talairach coordinates (Talairach and Tournoux, 1988). For the purpose of attributing anatomical areas to the activations depicted in the statistical analysis (as described below), the coordinates of the MNI template were transferred into a standardized stereotactic space (Talairach and Tournoux, 1988) using a program written by Brett et al. (2001). For the statistical analysis, task-related differences in global cerebral blood flow (CBF) within and between subjects were removed by treating global activity as a covariate. In this approach, state-dependent differences in global CBF related to the different conditions are systematically removed. For each pixel in the stereotactic space, this analysis of covariance (ANCOVA) generated a condition-specific adjusted mean regional CBF ( $\mathrm{rCBF}$ ) value, which was arbitrarily normalized to $50 \mathrm{ml} / \mathrm{min}$, with a corresponding adjusted error variance. This normalization allowed the planned comparisons of the mean CBF distributions across all sets of conditions and subjects.

In analyzing the data, the means were compared with $t$ statistics using the general linear approach and statistical parametric maps were generated. For the contrasts of interest, the significance of these maps was investigated by comparing the expected and observed distributions of the $t$ statistic under the null hypothesis of no differential effect on rCBF. The experimental conditions were compared between subjects by applying linear contrasts on the parameter estimates, which resulted in a $t$ statistic for each voxel. A design matrix was defined including all subjects and conditions of interest. Commonalities between the four tasks of interest were investigated by introducing the four contrasts- $(\mathrm{V}-\mathrm{B}),(\mathrm{N}-\mathrm{B}),(\mathrm{PV}-\mathrm{B})$, and $(\mathrm{PN}-\mathrm{B})$ - as a mask (thresholded at $P<0.05)$ for the contrast $(\mathrm{V}+\mathrm{N}+\mathrm{PV}+\mathrm{PN})$ versus $B$. Next we computed the following cognitive subtractions between noun and verb conditions: $(\mathrm{V}-\mathrm{N}),(\mathrm{N}-\mathrm{V}),(\mathrm{PV}-\mathrm{PN})$, and $(\mathrm{PN}-\mathrm{PV})$. Finally, we tested the differences between the grammatical classes irrespective of semantic content by computing the conjunctions $(\mathrm{V}-\mathrm{N}) \cap(\mathrm{PV}-\mathrm{PN})$ and $(\mathrm{N}-\mathrm{V}) \cap(\mathrm{PN}-$ PV).

Tables $1-5$ report clusters of activation surviving a threshold of $P<0.01$ with a cluster size of $k=20$ (uncorrected for multiple comparisons). To correct for the substantial possibility of type I errors (false positives) at this threshold, activations were considered for further analysis if they corresponded to regions identified in an earlier meta-analysis of 58 neuroimaging experiments of language production (Indefrey and Levelt, 2000). We focused on areas that had been implicated in word generation tasks specifically, or in lexical production tasks generally, with relative frequencies exceed-

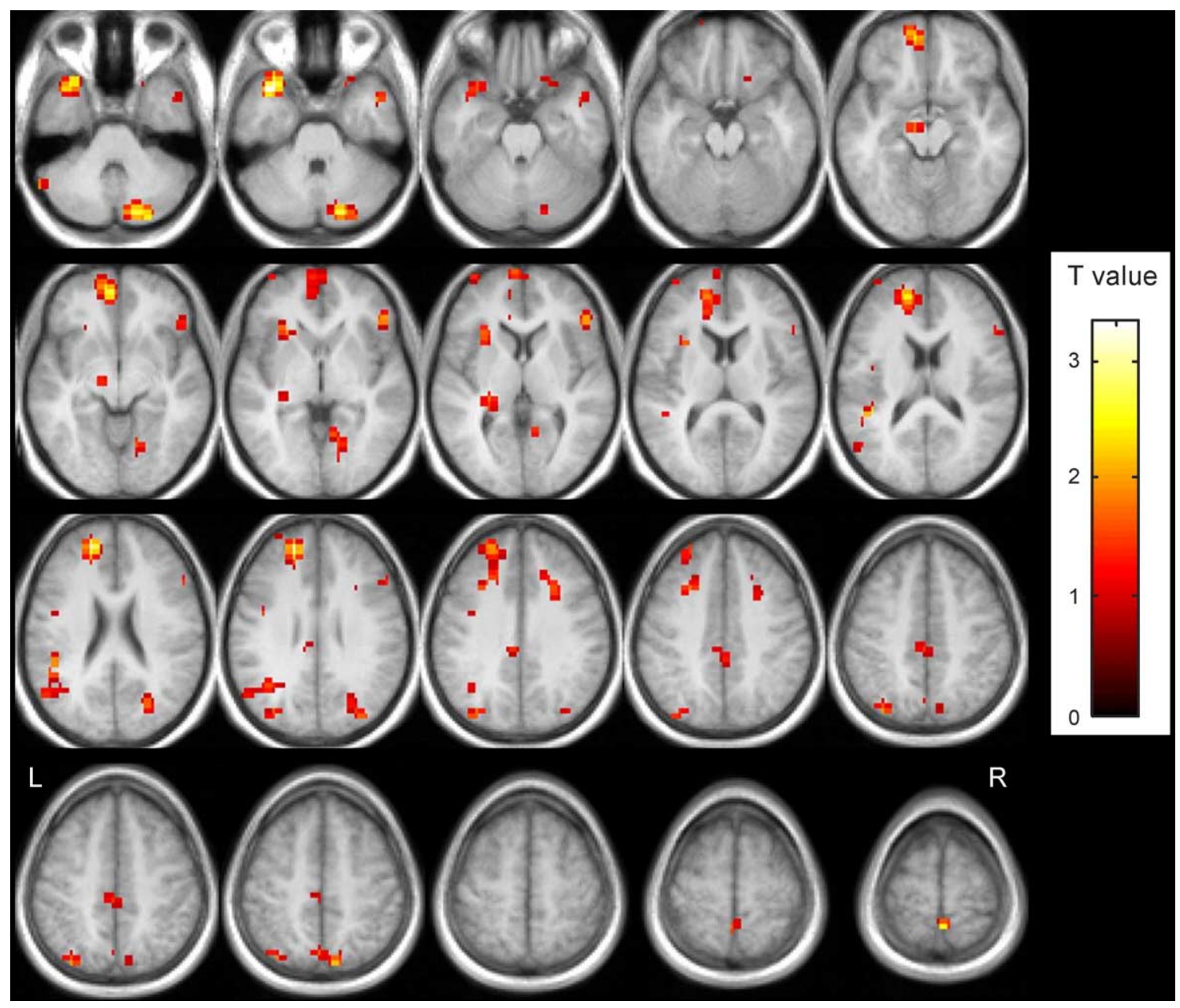

Fig. 2. Areas of greater activation for verbs compared to nouns $(V-N)$. 


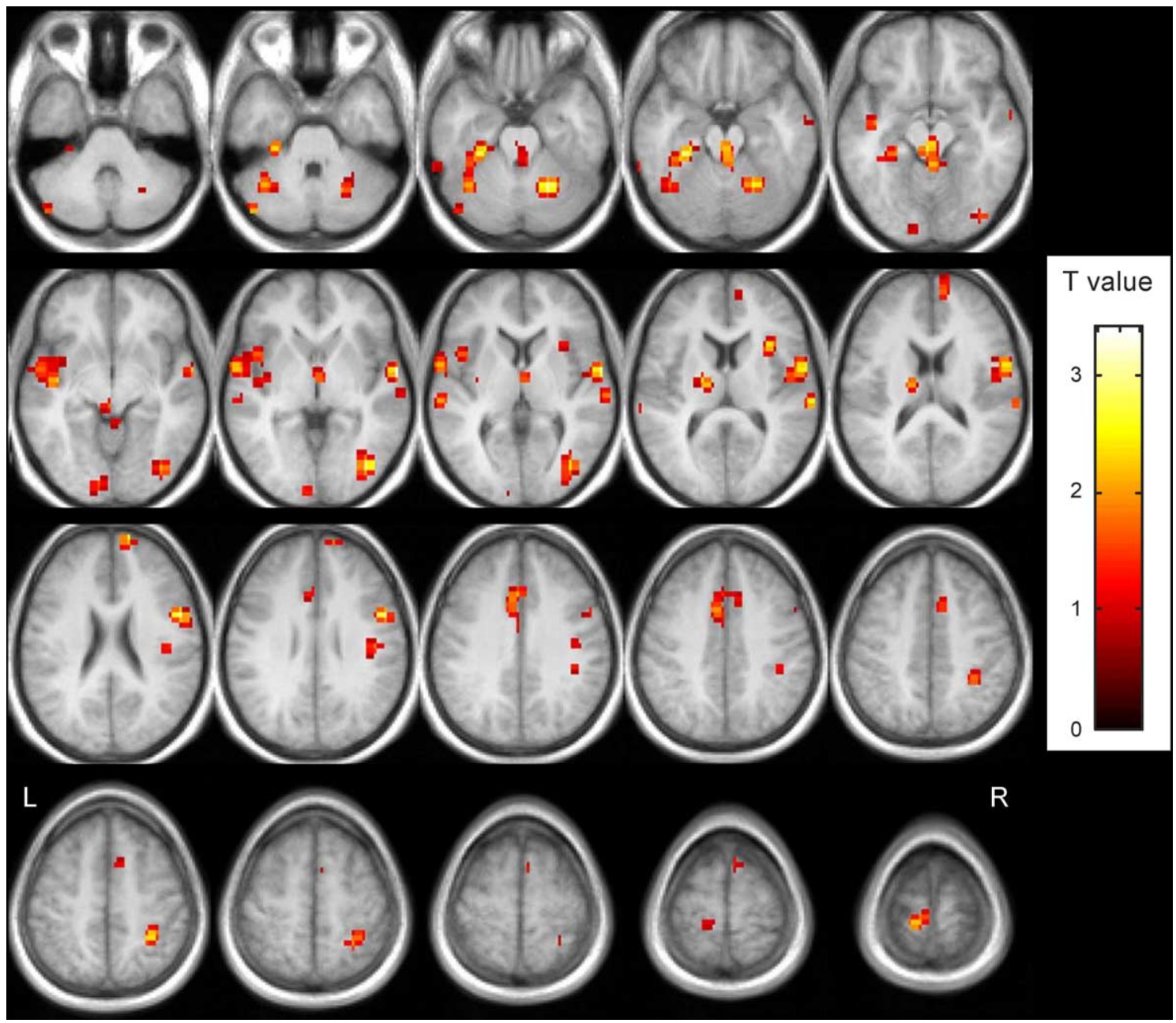

Fig. 3. Areas of greater activation for nouns compared to verbs $(\mathrm{N}-\mathrm{V})$.

ing the error probability threshold of $P<0.1$. A small volume correction was applied to activations meeting this criterion. Activations are reported in bold if they surpassed a small volume correction of $P<0.05$ at the cluster level, corrected for multiple comparisons. The small volume correction was performed sequentially in the brain areas of interest based on the method for small volume random field corrections described by Worsley et al. (1996).

\section{Results}

Behavioral results

Subjects performed the tasks correctly on about $95 \%$ of trials. There were no significant differences in accuracy between the various conditions (nouns, verbs, pseudonouns, and pseudoverbs).
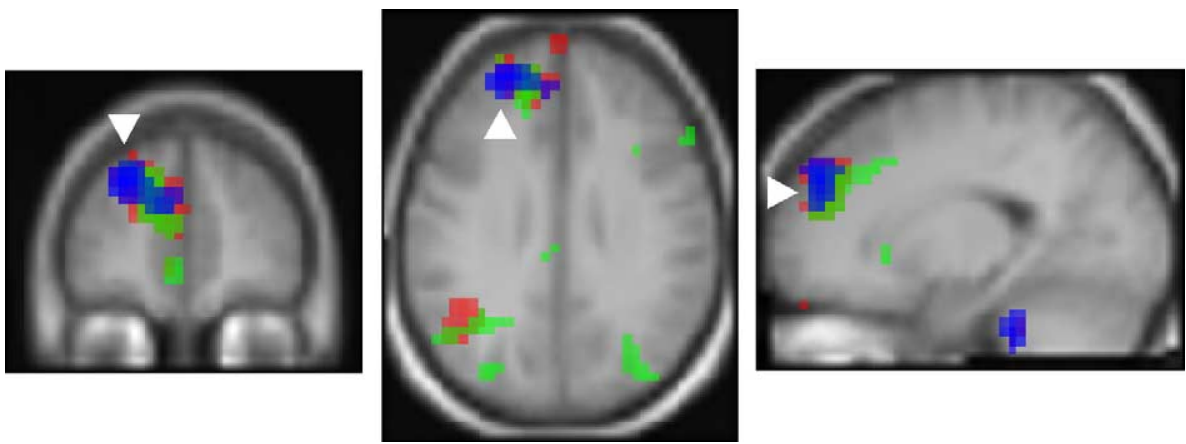

Fig. 4. Areas of overlap between contrasts showing greater activation for verbs (green), pseudoverbs (blue), and the conjunction of verbs and pseudoverbs (red) compared to relevant noun conditions. Arrows indicate an area of activation primarily within the left superior frontal gyrus that was activated for all three contrasts. 


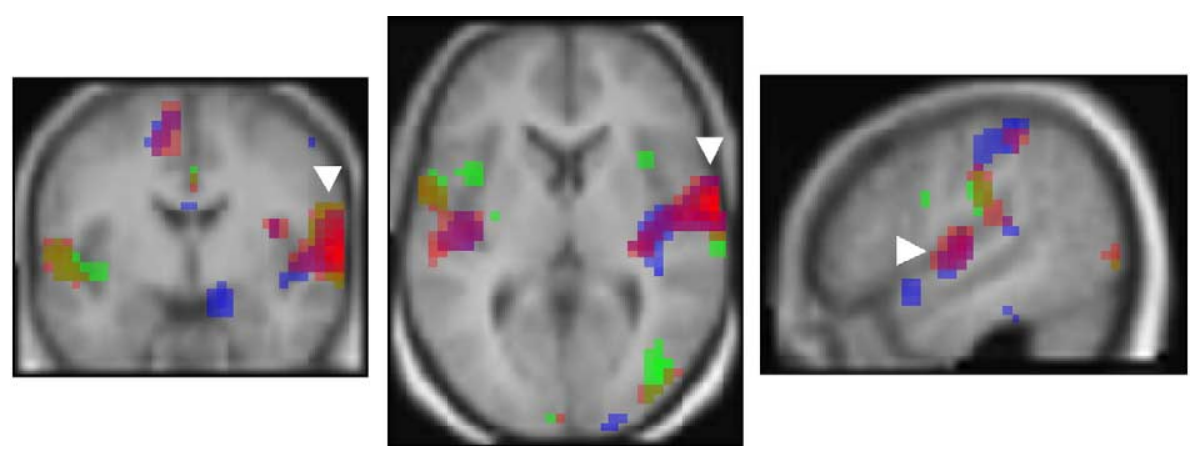

Fig. 5. Areas of overlap between contrasts showing greater activation for nouns (green), pseudonouns (blue), and the conjunction of nouns and pseudonouns (red) compared to relevant noun conditions. Arrows indicate an area of activation in the right superior temporal cortex that was activated for all three contrasts.

\section{PET Results}

The functional imaging data were analyzed in two steps. First, we evaluated the commonalities across activation patterns while subjects performed the grammatical task (plural or singular production of nouns, verbs, pseudonouns, and pseudoverbs) against a reference task in which subjects produced pseudowords without morphological change. This analysis revealed areas of activation within the left inferior and middle frontal gyri, the medial frontal gyrus merging into the anterior cingulate gyrus, the left primary motor cortex in the hand/mouth region, and within the right cerebellar hemisphere (Table 1, Fig. 1).

In the second step, the various task conditions were compared using cognitive subtractions in order to evaluate the specific differences between verbs and nouns or pseudoverbs and pseudonouns. In these analyses, verbs (Table 2, Fig. 2) and pseudoverbs (Table 3 ) produced more robust activation within the left rostral prefrontal cortex, especially in the anterior portion of the left superior frontal gyrus, in comparison to nouns and pseudonouns, respectively. Real verbs produced additional activation in the left inferior frontal gyrus (including Broca's area) and in the right cerebellar hemisphere, while activation for pseudoverbs was observed in the anterior portion of the right middle temporal gyrus and in the left cerebellum.

The reverse contrasts revealed more extensive recruitment of temporoparietal areas bilaterally. Real nouns (Table 2, Fig. 3) and pseudonouns (Table 3 ) both elicited activation in the middle part of the right superior temporal gyrus. Other areas of activation for real nouns were observed in middle portions of the fusiform gyrus on the left, in addition to the right insula and right cerebellum. By contrast, pseudowords used as nouns activated the left inferior frontal cortex and left insular regions.

This double dissociation was confirmed in an analysis that collapsed across the pseudoword and real word conditions for nouns and verbs (Tables $4 \mathrm{a}$ and $4 \mathrm{~b}$ ). The conjunction of the contrasts $(\mathrm{V}-\mathrm{N})$ and $(\mathrm{PV}-\mathrm{PN})$ yielded significant activation in the left superior frontal gyrus extending anteriorly (Fig. 4), consistent with both simple contrasts. Nouns and pseudonouns commonly activated the middle portion of the right superior temporal gyrus (Fig. 5) and the left fusiform gyrus (Fig. 6). A summary of significant cortical activations for both the simple contrasts and the conjunctions is given in Table 5. In the discussion that follows, we focus on brain areas activated in the conjunction of real word and pseudoword contrasts with a significance exceeding the threshold $P<0.02$.

\section{Discussion}

There is a fair amount of evidence that, in addition to relying on a common language network, verbs or nouns are processed by spatially and/or functionally distinct neural populations. This conclusion is supported by neuropsychological reports of double dissociations in noun and verb production (Damasio and Tranel, 1993; Daniele et al., 1994; Shapiro and Caramazza, 2003), as well as by electrophysiological measures (Kellenbach et al., 2002; Koenig and Lehmann, 1996; Tyler et al., 2001).

However, previous functional imaging studies have not revealed clear-cut dissociations between the two categories. In experimental tasks ranging from word generation (Warburton et al., 1996) to

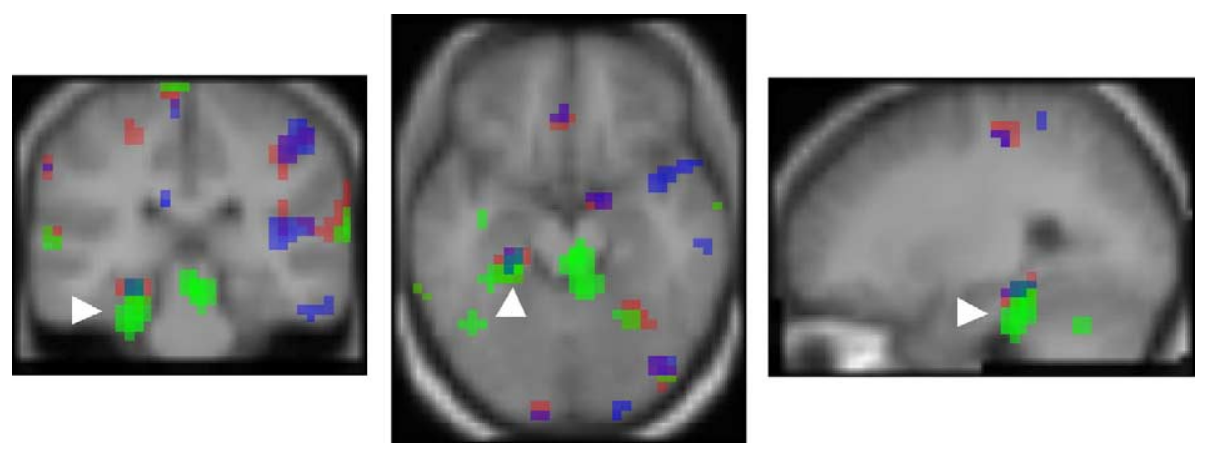

Fig. 6. Areas of overlap between contrasts showing greater activation for nouns (green), pseudonouns (blue), and the conjunction of nouns and pseudonouns (red) compared to relevant noun conditions. Arrows indicate an area of activation in the left inferior temporal cortex that was activated for the contrasts ( $\mathrm{N}-\mathrm{V})$ and the conjunction $(\mathrm{N}-\mathrm{V}) \cap(\mathrm{PN}-\mathrm{PV})$. 
word stem completion (Buckner et al., 2000) and semantic categorization (Tyler et al., 2001), nouns and verbs both activate a patchwork of areas in the left hemisphere, including temporal, parietal, and prefrontal regions, with no consistent differences across grammatical category. One study using a lexical decision paradigm showed that some areas in the left hemisphere, including dorsolateral prefrontal cortex and parts of the parietal and temporal lobes, were activated more robustly for verbs than for nouns, but the experimenters did not find any areas in which nouns elicited greater activity (Perani et al., 1999).

We have suggested that the absence of differences between nouns and verbs in these studies may owe more to the demands of the tasks employed than to the existence of a nondifferentiated neural system for processing words of different types. Many of the functional imaging studies described above appear to share the assumption that the same neural mechanisms are engaged in word comprehension and production; in particular, they have sought to replicate neuropsychological dissociations in naming tasks with paradigms geared more toward comprehension. However, some neurological patients who present with difficulties in producing nouns or verbs in spontaneous speech and picture naming tasks do not show the same effects in lexical decision and semantic judgment tasks (Hillis and Caramazza, 1995; Shapiro et al., 2000), suggesting that their deficits specifically affect the production of words of one grammatical category. In a few reported cases, this production deficit is further limited to either spoken or written output (Caramazza and Hillis, 1991; Hillis et al., 2002b; Rapp and Caramazza, 1997). It is unclear to what degree extant functional imaging studies address these issues raised in the neuropsychological literature.

The morphological task used in the present study is comparable to tasks we have used with two patients, who make errors when asked to produce grammatical forms of real words and pseudowords used either as nouns (Shapiro et al., 2000) or as verbs (Shapiro and Caramazza, 2003). Moreover, in a study with TMS, we demonstrated that transient suppression of the left frontal cortex delays performance of the task with verbs and pseudoverbs, but not with nouns or pseudonouns (Shapiro et al., 2001).

In the context of these previous studies, we approached the results of the current experiments in a hypothesis-driven way to reveal small differences in healthy native speakers of German. In this sense, the results reported here expand upon earlier findings by illuminating the cortical networks engaged in performing the morphological task with nouns and verbs. Our data corroborate the notion that nouns and verbs are processed by a common cortical network mainly within the left hemisphere, with additional category-sensitive processes in the left rostral prefrontal cortex (for verbs) and bilateral temporal cortices (for nouns).

\section{Differences in noun and verb processing}

Verb production deficits are most often associated with lesions either in the left frontal cortex, including prefrontal/premotor areas and underlying white matter, and anterior insular cortex (Damasio and Tranel, 1993; Daniele et al., 1994; Hillis et al., 2002a; Miceli et al., 1984), or else in parts of the left parietal lobe (Silveri and di Betta, 1997). We found that performing a grammatical manipulation with both verbs and pseudoverbs (compared to nouns and pseudonouns) reliably activated parts of the left rostral prefrontal cortex-in particular, in the left superior frontal gyrus, anterior and superior to regions damaged in a patient with selective difficulties in grammatical processing of verbs and pseudoverbs (Shapiro and Caramazza, 2003). Several previous PET studies have observed activation in this area for verb generation compared to silent rest (Crivello et al., 1995; Herholz et al., 1996; Warburton et al., 1996).

By contrast, impairments in noun production generally have been linked to damage in the left temporal lobe (Damasio and Tranel, 1993; Daniele et al., 1994; Silveri and di Betta, 1997). Although we did find areas within the left temporal lobe that were more strongly activated by production of nouns than of verbs (i.e., in the middle portion of the left fusiform gyrus), significant activation was also observed for both nouns and pseudonouns in the middle portion of the right superior temporal gyrus. The finding that noun processing engages structures in both the left and right temporal lobes is in agreement with earlier PET studies of object naming (Martin et al., 1996; Warburton et al., 1996) and suggests that the cortical network specialized for noun processing may be distributed bilaterally.

\section{Bilateral processing of nouns}

There is substantial converging evidence to suggest that right hemisphere structures may play a role in noun naming specifically. Such evidence comes primarily from reports of dextral patients with optic aphasia (Coslett and Saffran, 1989, 1992) and other language deficits resulting from right hemisphere damage (Cappa et al., 1990), as well as from split-brain patients (Gazzaniga, 1983; Gazzaniga and Sperry, 1967; Zaidel, 1976, 1983). Moreover, visual half-field research has shown that verbs are processed faster in the left hemisphere compared to the right, while there is no hemispheric advantage for the processing of concrete nouns (Day, 1979; Eviatar et al., 1990; Nieto et al., 1999; Sereno, 1999).

Recruitment of the right hemisphere in recognition and production tasks involving concrete nouns has most often been explained as reflecting the retrieval of specific sensory-semantic properties of objects (Coslett and Saffran, 1992; Day, 1977; Eviatar et al., 1990). However, we observed robust right-sided activity in response to pseudonouns, which are not obviously linked to stored visual or sensory properties. It seems unlikely a fortiori that this activation was related to grammatical processing.

One possibility is that subjects in our study regarded pseudonouns as referring generically to objects. If this were true, rightsided superior temporal activity - and, indeed, activity within the left inferior temporal cortex, particularly the fusiform gyrus, which has been implicated in object recognition and attribute knowledge (Chao et al., 1999; for review see Tarr and Cheng, 2003)—might reflect incidental activation of semantic or visual-sensory features associated with object names.

Such a strategy may have been encouraged by the structure of the task since the production of plural morphology for nouns arguably has some semantic implications - to wit, plural nouns refer to countable entities. This is not necessarily true in the case of verbs: because plural morphology for verbs is merely a formal reflex of a structural relationship between words in an utterance, verb and pseudoverb processing might not have engaged areas involved in representing meaning to the same extent as noun processing. Moreover, it seems unlikely that the left superior frontal gyrus, which was engaged selectively for verb and 
pseudoverb production in this experiment, is critical for the retrieval of semantic information (although we cannot rule out this possibility, especially in light of evidence that the same cortical area may be involved in silent verb generation to noun cues; Crivello et al., 1995; Herholz et al., 1996).

A viable alternative interpretation is that the left superior frontal gyrus is important not for morphological processing of verbs in general, but rather for the specific morphological and syntactic operation employed in this task (i.e., subject-verb agreement). Neuropsychological studies (Shapiro and Caramazza, 2003) and experiments with TMS (Shapiro et al., 2001) have suggested that more inferior neural structures, particularly the portion of the left middle frontal gyrus anterior and superior to Broca's area, may be implicated in agreement and other morphological transformations, including past tense formation. If the more superior area identified here is involved in morphological processing, further experiments are needed to determine whether the area shares this function or rather plays a more specific role in the computation of verbal agreement.

\section{Conclusion}

In this study, we used a production task emphasizing the grammatical role of nouns and verbs in an effort to reveal the neural substrates of knowledge about words of these two categories. An important advantage of the morphological task over tasks that have previously been used in functional imaging studies is that it can be used with pseudowords as well as real words, allowing us to examine grammatical processing independently of word meaning. Production of real verbs and of pseudowords used as verbs (relative to nouns) resulted in activation of areas in the left rostral prefrontal cortex, while the reverse contrast revealed greater activation in bilateral temporal areas.

We note that not all of the areas in which we found activation need logically be involved in grammatical processing. Some of the activation differences may reflect other aspects of language production, in particular, the retrieval of sensorimotor and semantic information associated with word meanings. However, we think it is unlikely that the differential patterns of activation we observed in noun and verb production are entirely attributable to differences in conceptual or semantic processing since previous PET studies that focused explicitly on semantic judgments have failed to distinguish areas specific to words of either category (Tyler et al., 2001; Warburton et al., 1996). This suggests that the cortical dissociations found in the present study were driven in part by the distinct grammatical roles of nouns and verbs in spoken word production, at least in particular syntactic contexts (i.e., plural production and subject-verb agreement). These functional roles may in turn entail access to different kinds of semantic representations, some of which may be distributed bilaterally in the brain.

\section{Acknowledgments}

The work reported here was supported in part by NIH grant DC04542. We are grateful for the help of the PET group (Prof. H. Herzog, director) and the MRI group (Dr. N. J. Shah, director) at the Institute of Medicine, Research Center Jülich, Germany.
We also thank Dr. L. Moo for her helpful comments and suggestions.

\section{References}

Brett, M., Christoff, K., et al., 2001. Using the Talairach atlas with the MNI template. NeuroImage 13, S85.

Brix, G., Zaers, J., et al., 1997. Performance evaluation of a whole-body PET scanner using the NEMA protocol. National Electrical Manufacturers Association. J. Nucl. Med. 38 (10), 1614-1623.

Buckner, R.L., Koutstaal, W., et al., 2000. Functional MRI evidence for a role of frontal and inferior temporal cortex in amodal components of priming. Brain 123 (Pt. 3), 620-640.

Cappa, S.F., Papagno, C., et al., 1990. Language and verbal memory after right hemispheric stroke: a clinical-CT scan study. Neuropsychologia 28 (5), 503-509.

Caramazza, A., Hillis, A.E., 1991. Lexical organization of nouns and verbs in the brain. Nature 349 (6312), 788-790.

Chao, L.L., Haxby, J.V., et al., 1999. Attribute-based neural substrates in temporal cortex for perceiving and knowing about objects. Nat. Neurosci. 2 (10), 913-919.

Coslett, H.B., Saffran, E.M., 1989. Preserved object recognition and reading comprehension in optic aphasia. Brain 112 (Pt. 4), 1091-1110.

Coslett, H.B., Saffran, E.M., 1992. Optic aphasia and the right hemisphere: a replication and extension. Brain Lang. 43 (1), 148-161.

Crivello, F., Tzourio, N., et al., 1995. Intersubject variability in functional neuroanatomy of silent verb generation: assessment by a new activation detection algorithm based on amplitude and size information. NeuroImage 2, 253-263.

Damasio, A., Tranel, D., 1993. Nouns and verbs are retrieved with differentially distributed neural systems. Proc. Natl. Acad. Sci. 90, 4957-4960.

Daniele, A., Giustolisi, L., et al., 1994. Evidence for a possible neuroanatomical basis for lexical processing of nouns and verbs. Neuropsychologia 32 (11), 1325-1341.

Day, J., 1977. Right-hemisphere language processing in normal righthanders. J. Exp. Psychol. Hum. Percept. Perform. 3 (3), 518-528.

Day, J., 1979. Visual half-field word recognition as a function of syntactic class and imageability. Neuropsychologia 17, 515-519.

Eviatar, Z., Menn, L., et al., 1990. Concreteness: nouns, verbs, and hemispheres. Cortex 26 (4), 611-624.

Gazzaniga, M.S., 1983. Right hemisphere language following brain bisection. A 20-year perspective. Am. Psychol. 38 (5), 525-537.

Gazzaniga, M.S., Sperry, R.W., 1967. Language after section of the cerebral commissures. Brain 90 (1), 131-148.

Goodglass, H., Klein, B., et al., 1966. Specific semantic word categories in aphasia. Cortex 2, 74-89.

Grossman, M., Koenig, P., et al., 2002. Neural representation of verb meaning: an fMRI study. Hum. Brain Mapp. 15, 124-134.

Herholz, K., Thiel, A., et al., 1996. Individual functional anatomy of verb generation. NeuroImage 3, 185-194.

Herzog, H., Seitz, R.J., et al., 1994. Pharmacokinetics and radiation dose of oxygen-15 labelled butanol in rCBF studies in humans. Eur. J. Nucl. Med. 21 (2), 138-143.

Hillis, A.E., Caramazza, A., 1995a. Representation of grammatical categories of words in the brain. J. Cogn. Neurosci. 7 (3), 396-407.

Hillis, A.E., Tuffiash, E., et al., 2002b. Regions of neural dysfunction associated with impaired naming of actions and objects in acute stroke. Cogn. Neuropsychol. 19 (6), 523-534.

Hillis, A.E., Wityk, R.J., et al., 2002. Neural regions essential for writing verbs. Nat. Neurosci. 6, 19-20.

Indefrey, P., Levelt, W.J.M., 2000. The neural correlates of language production. In: Gazzaniga, M. (Ed.), The New Cognitive Neurosciences. MIT Press, Cambridge, MA.

Kable, J.W., Lease-Spellmeyer, J., et al., 2002. Neural substrates of action event knowledge. J. Cogn. Neurosci. 14, 795-805. 
Kellenbach, M.L., Wijers, A.A., et al., 2002. Neural differentiation of lexico-syntactic categories or semantic features? Event-related potential evidence for both. J. Cogn. Neurosci. 14 (4), 561-577.

Kinahan, P.E., Rogers, J.G., 1989. Analytic 3D image reconstruction using all detected events. IEEE Trans. Nucl. Sci. 35, 680-684.

Koenig, T., Lehmann, D., 1996. Microstates in language-related brain potential maps show noun-verb differences. Brain Lang. 53, 169-182.

Luria, A.R., Tsvetkova, L.S., 1967. Towards the mechanisms of "dynamic aphasia”. Acta Neurol. Psychiatr. Belg. 67 (11), 1045-1057.

Martin, A., Wiggs, C.L., et al., 1996. Neural correlates of category-specific knowledge. Nature 379 (6566), 649-652.

McCarthy, R., Warrington, E.K., 1985. Category specificity in an agrammatic patient: the relative impairment of verb retrieval and comprehension. Neuropsychologia 23 (6), 709-727.

Miceli, G., Silveri, M.C., et al., 1984. On the basis for the agrammatic's difficulty in producing main verbs. Cortex 20 (2), 207-220.

Nieto, A., Santacruz, R., et al., 1999. Hemispheric asymmetry in lexical decisions: the effects of grammatical class and imageability. Brain Lang. 70 (3), 421-436.

Penke, M., Krause, M., 2002. German noun plurals: a challenge to the dualmechanism model. Brain Lang. 81 (1/2/3), 303-311.

Perani, D., Cappa, S.F., et al., 1999. The neural correlates of verb and noun processing. A PET study. Brain 122 (Pt. 12), 2337-2344.

Pulvermuller, F., 1999. Words in the brain's language. Behav. Brain Sci. 22 (2), 253-279 (discussion 280-336).

Rapp, B., Caramazza, A., 1997. The modality-specific organization of grammatical categories: evidence from impaired spoken and written sentence production. Brain Lang. 56 (2), 248-286.
Sereno, J.A., 1999. Hemispheric differences in grammatical class. Brain Lang. 70 (1), 13-28.

Shapiro, K., Caramazza, A., 2003. Grammatical processing of nouns and verbs in left frontal cortex? Neuropsychologia 41 (9), 1189-1198.

Shapiro, K., Shelton, J., et al., 2000. Grammatical class in lexical production and morphological processing: evidence from a case of fluent aphasia. Cogn. Neuropsychol. 17 (8), 665-682.

Shapiro, K.A., Pascual-Leone, A., et al., 2001. Grammatical distinctions in the left frontal cortex. J. Cogn. Neurosci. 13 (6), 713-720.

Silveri, M.C., di Betta, A., 1997. Noun-verb dissociations in brain damaged patients: further evidence. Neurocase 3, 477-488.

Talairach, J., Tournoux, P., 1988. Co-planar Stereotaxic Atlas of the Human Brain. Thieme Medical Publishers, Inc., New York.

Tarr, M.J., Cheng, Y.D., 2003. Learning to see faces and objects. Trends Cogn. Sci. 7, 23-30.

Tranel, D., Damasio, H., et al., 1997. On the neurology of naming. In: Goodglass, H. (Eds.), Anomia. Academic Press, London, pp. 65-90.

Tyler, L.K., Russell, R., et al., 2001. The neural representation of nouns and verbs: PET studies. Brain 124 (Pt. 8), 1619-1634.

Warburton, E., Wise, R., et al., 1996. Noun and verb retrieval by normal subjects: studies with PET. Brain 119, 159-179.

Worsley, K.J., Marrett, S., et al., 1996. A unified statistical approach for determining significant signals in images of cerebral activation. Hum. Brain Mapp. 4, 58-73.

Zaidel, E., 1976. Auditory vocabulary of the right hemisphere following brain bisection or hemidecortication. Cortex 12 (3), 191-211.

Zaidel, E., 1983. A response to Gazzaniga. Language in the right hemisphere, convergent perspectives. Am. Psychol. 38 (5), 542-546. 